\title{
The Correlation of Collateral Circulation and Age during Acute Ischemic Heart Disease
}

\author{
Maia Chigogidze (MD, PhD Student) \\ Ivane Javakhishvili Tbilisi State University, Tbilisi, Georgia \\ Nino Sharashidze (MD, PhD, Professor) \\ Ivane Javakhishvili Tbilisi State University, Tbilisi, Georgia \\ Zurab Pagava (MD, PhD, Professor) \\ Ivane Javakhishvili Tbilisi State University, Tbilisi, Georgia \\ IamzeTaboridze (PhD, Professor) \\ David Aghmashenebeli University of Georgia, Georgia
}

Doi:10.19044/esj.2020.v16n18p335 URL:http://dx.doi.org/10.19044/esj.2020.v16n18p335

\begin{abstract}
Background: Coronary collaterals (CC) are alternative sources of blood supply to myocardium jeopardized by Ischemia. Aim: To investigate the dependence and influence of collateral circulation on age during acute ischemic heart disease. Methods: Analysis shows that 673 patients were studied from the SamgoriMedi Clinic (Tbilisi, Georgia) aged 27-94 years $(64.7+11.48)$ with acute coronary syndromes. Basic medical data such as sex, age, cardiovascular risk factors, angina pectoris, revascularization history, echocardiography, and laboratory data were obtained from the patient's medical records. CC vessels were graded according to the Rentrop grading system of 0 to 3. Results: The development index of collateral circulations visibly increases with age. Average age increases accordingly as follows: rentrop 0 - 62.85 \pm 12.01 , rentrop 1 - 64.90 \pm 10.79 , rentrop $2-66.84 \pm 10.49$, and rentrop $3-69.04 \pm 9.68(\mathrm{p}<0.0001)$. There is positive significant correlation between the development of collateral circulation and age groups $\mathrm{r}=0.170^{* *}$, $\mathrm{p}<0.001$. The cases of female sex, hypertension, acute MI without ST elevation, CABG frequency (also EF\% - 35-45\%, <35\%), and multiple vessel coronary lesion are noticed to increase with age, while the male sex and EF (ejection fraction) $>45 \%$ cases decreases with age. Conclusion Collateral circulation shows significantly positive correlation with age and female sex. However, it should be mentioned that in elderly patients with a high ejection fraction and normal diastolic function, the development of collateral vessels is low.
\end{abstract}

Keywords: Coronary collateral circulation, age, correlation 


\section{Introduction}

Coronary collaterals are alternative source of blood supply to myocardium jeopardized by ischemia (Seiler, 2010). Among individuals who are not suffering from coronary artery disease (CAD), collateral arteries are performed in preventing myocardial ischemia during a brief vascular occlusion in 20-25\% (Meier et al., 2013). Determinants of such anastomoses are low heart rate and the absence of systemic arterial hypertension. In patients with CAD, collateral arteries preventing myocardial ischemia during a brief occlusion are presented in every third individual. Collateral flow is sufficient to prevent myocardial ischemia during coronary occlusion amounts from onefifth to one-fourth the normal flow through the open vessel (Seiler et al., 2013; Bhatnagar et al., 2019). It is suggested that coronary collaterals are important in preserving left ventricular systolic and diastolic performance at least while resting. Not easily visible collaterals may also prevent systolic dysfunction (Carmel et al., 1998; Dai et al., 2020). The presence of CCC reduces postoperative myocardial injury, low cardiac output syndrome, and mortality rates (Ucak et al., 2019).

Collateral circulation does not occur until the age of 30 , and it is observed only in 23\% of patients with age range of 31-40 (Zimmerman et al., 2005). However, in case of stimulus for developing the collateral pathways implying long-term angina, followed by severe coronary stenosis, the patient's age is crucial and this determines the development of collateral circulation. Moreover, collateral pathways develop more efficiently in young aged patients (Nakae et al., 2000). The total number of collateral pathways decreases with ageing in elder patients (Balci, 2004).

Regardless of the fact that studies have shown both age-related changes for blood vessels including arterial remodeling (Wang et al., 2010), as well as age-related functional decline of collateral circuits (Kurotobi et al., 2004), there are no studies which would let us define the specific influence of age on remodeling process so far (Balci et al., 2004).

Consequently, our research aims to study the dependence and influence of collateral circulation on age during acute ischemic heart disease.

\section{Materials and Methods}

Analysis shows that 673 Patients, aged $27-94$ years $(64.7+11.48)$ with acute coronary syndromes, who underwent coronary angiography at the Department of Cardiology, SamgoriMedi Clinic (Tbilisi, Georgia) between January 2014 and January 2017 were evaluated and diagnosed with CAD.

Patients have given the consent to participate in the research study. The study protocol was approved by the local ethics committee. Clinical and laboratory data were obtained from the patients' medical records.

Basic clinical data, including sex, age, cardiovascular risk factors such 
as hypertension, diabetes mellitus (DM), Dyslipidemia, TIA, smoking status, relevant medication, course of $\mathrm{CAD}$, angina pectoris, revascularization (coronary artery bypass graft operation or percutaneous coronary intervention) history, ultrasound parameters of left ventricular systolic and diastolic function, ejection fraction, regional wall motion abnormalities, systolic and diastolic blood pressure were obtained from the patient's medical records. Diabetes Mellitus (DM) was defined as a history of DM, which is the use of antidiabetic drugs or fasting plasma glucose levels of $\geq 7 \mathrm{mmol} / \mathrm{L}$. Hypertension (HT) was defined as a history of HT or use of antihypertensive drugs, or a blood pressure $\geq 140 / 90 \mathrm{mmHg}$. Smoking status was defined as current smoking.

Patients with renal dysfunction (serum creatinine level $>132.6$ $\mu \mathrm{mol} / \mathrm{L}$ ), revascularization (coronary artery bypass graft operation or percutaneous coronary intervention) history, severe valvular disease, myocardial or pericardial disease, and technically inadequate coronary angiography were excluded from the study. Patients who were diagnosed with hematological disease, cancer, systemic inflammatory or autoimmune disease, thrombocytopenia, and the use of anticoagulant agents were also excluded from the study.

\section{Angiographic Evaluation and CC Grading}

Coronary angiography was performed through the Radial artery to all patients using the Seldinger technique. Each angiogram was interpreted by two experienced cardiologists who were not familiar with the clinical details and results of the other investigations of each patient.

$\mathrm{CC}$ vessels were graded according to the Rentrop grading system of 0 to 3:

$0=$ no filling of any collateral vessel;

$1=$ filling of the side branches of the artery to be perfused by collateral vessels without visualization of the epicardial segment;

$2=$ partial filling of the distal epicardial segment by collateral vessels;

$3=$ complete filling of the distal epicardial segment by collateral vessels.

\section{Statistical Analysis}

Continuous variables are expressed as $\pm \mathrm{SD}$, and categorical variables as frequencies and \%. Continuous variables were compared with the use of the one way ANOVA and Post Hoc Tests, while categorical variables were compared with the use of the Fisher's Exact Test. Correlation analysis between categorical variables was performed by Spearman correlation analysis. P value $<0.05$ was considered as statistically significant. All statistical analysis was performed using SPSS version 23. 


\section{Results}

Collateral circulations that were explored and performed in our study appeared to be related with both singular and multiple vessel occlusions. Thus, the distribution of collateral circulation degree by involved blood vessels is given in Figure 1.

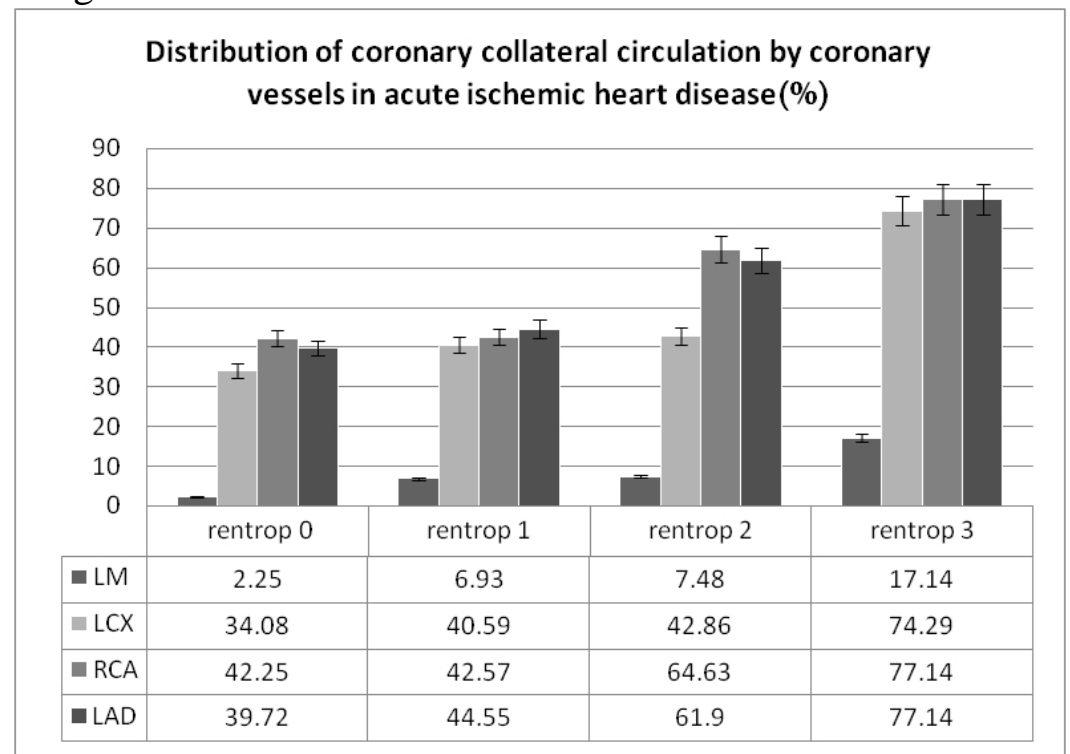

Figure 1.Frequency of LAD, LCX and RCA increases with rentrop. For LM, collateralization is little and does not show any significant variation related to rentrop.

Age data of patients according to collateral circulation degrees is given in Table 1.

Table 1. Distribution of patients' age data according to rentrop

\begin{tabular}{|c|c|c|c|c|c|c|}
\hline & $\mathrm{N}$ & Mean+SD & Minimum & Maximum & $\mathrm{F}$ & $\mathrm{P}$ \\
\hline Rentrop0 & 355 & $62.85 \pm 12.01$ & 27.00 & 92.00 & & \\
\cline { 1 - 5 } Rentrop1 & 101 & $64.90 \pm 10.79$ & 40.00 & 94.00 & \multirow{3}{*}{$\mathbf{8 . 4 0}$} & $<0.0001$ \\
\hline Rentrop2 & 147 & $66.84 \pm 10.49$ & 41.00 & 87.00 & & \\
\hline Rentrop3 & 70 & $69.04 \pm 9.68$ & 47.00 & 87.00 & & \\
\hline
\end{tabular}

According to the chart represented above, the development index of collateral circulations confidently increases with age. In addition, in case of rentrop 0 , minimal age is 27 years. On the other hand, rentrop 1-2 corresponds to 41-42 years, and rentrop 3 corresponds to 47 years. The mean age is confidently low in rentrop 0 case. In addition, this group includes the lowest index of minimum age, which also shows the tendency of growth with age. Multiple comparisons (Post Hoc Tests) show that there is a significant age difference in the following groups: rentrop 0 - rentrop $2(\mathrm{p}<0.0001)$, rentrop 1 - rentrop $3(\mathrm{p}=0.0190)$, and rentrop0 - rentrop3 $(\mathrm{p}<0.0001)$.

Therefore, Figure 2 shows age-related distribution of collateral circulation. 


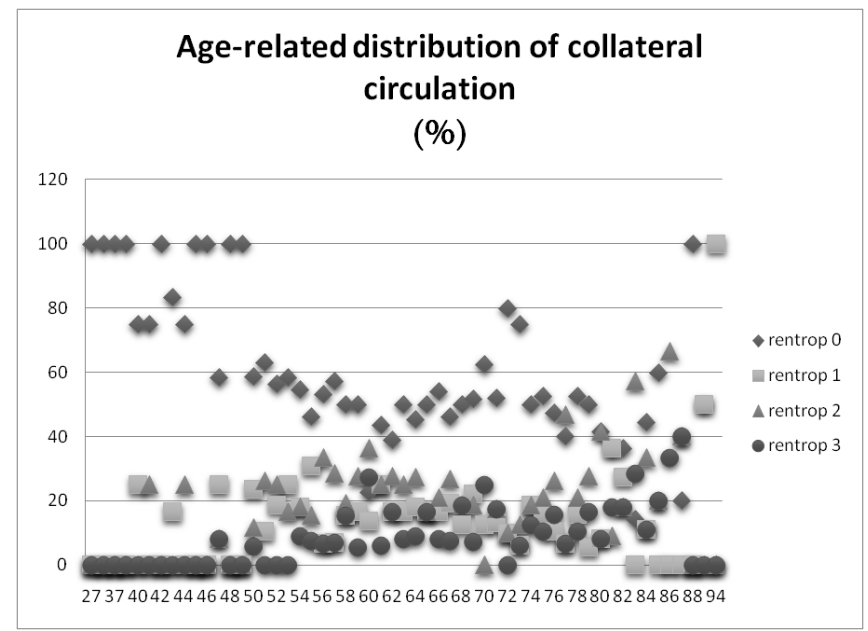

Figure 2.

As shown in the diagram above, undeveloped collateral circulation is observed with high frequency among all age groups. The maximum age for 01 degree is 92-94 years, and 87 years for 2-3 degree. Correlation analysis proved statistically confident positive link between development of collateral circulation and age groups $\mathrm{r}=0.170^{* *}, \mathrm{p}<0.001$. To determine what defines the age-related variations of collateral circulation, we studied the distribution of ischemic heart disease characteristics in different age groups (Table 2).

Table 2. Distribution of ischemic heart disease characteristics according to age

\begin{tabular}{|c|c|c|c|c|c|c|c|c|c|c|}
\hline & \multicolumn{2}{|c|}{$<56$} & \multicolumn{2}{|c|}{$56-65$} & \multicolumn{2}{|c|}{$66-75$} & \multicolumn{2}{|c|}{$>75$} & \multirow[b]{2}{*}{$\mathrm{F}$} & \multirow[b]{2}{*}{$\mathrm{p}$} \\
\hline & abs & $\%$ & $\begin{array}{c}\mathrm{Ab} \\
\mathrm{s}\end{array}$ & $\%$ & $\begin{array}{c}\mathrm{ab} \\
\mathrm{s}\end{array}$ & $\%$ & $\begin{array}{c}\mathrm{ab} \\
\mathrm{s}\end{array}$ & $\%$ & & \\
\hline Female & 20 & 13.25 & 53 & 26.63 & 81 & 43.78 & 82 & 59.42 & 30.05 & $<0.0001$ \\
\hline Male & 131 & 86.75 & 146 & 73.37 & $\begin{array}{c}10 \\
4\end{array}$ & 56.22 & 56 & 40.58 & 30.05 & $<0.0001$ \\
\hline Hypertension & 94 & 62.25 & 146 & 73.37 & $\begin{array}{c}15 \\
7\end{array}$ & 84.86 & $\begin{array}{c}12 \\
2\end{array}$ & 88.41 & 12.88 & $<0.0001$ \\
\hline $\begin{array}{l}\text { Diabetes } \\
\text { melitus }\end{array}$ & 20 & 13.25 & 44 & 22.11 & 54 & 29.19 & 28 & 20.29 & 4.27 & 0.0053 \\
\hline Dyslipidemia & 50 & 33.11 & 89 & 44.72 & 93 & 50.27 & 54 & 39.13 & 3.73 & 0.0112 \\
\hline $\begin{array}{l}\text { Acute } \\
\text { myocardial } \\
\text { infarction with } \\
\text { ST elevation }\end{array}$ & 51 & 33.77 & 83 & 41.71 & 59 & 31.89 & 46 & 33.33 & 1.63 & 0.1814 \\
\hline $\begin{array}{l}\text { Acute } \\
\text { myocardial } \\
\text { infarction } \\
\text { without ST } \\
\text { elevation }\end{array}$ & 47 & 31.13 & 60 & 30.15 & 72 & 38.92 & 55 & 39.86 & 1.92 & 0.1256 \\
\hline Unstable angina & 53 & 35.10 & 56 & 28.14 & 54 & 29.19 & 37 & 26.81 & 0.97 & 0.4066 \\
\hline$>5$ years & 6 & 3.97 & 15 & 7.54 & 18 & 9.73 & 21 & 15.22 & 4.02 & 0.0076 \\
\hline TIA & 10 & 6.62 & 13 & 6.53 & 12 & 6.49 & 11 & 7.97 & 0.12 & 0.9499 \\
\hline
\end{tabular}




\begin{tabular}{|l|c|c|c|c|c|c|c|c|c|c|}
\hline $\begin{array}{l}\text { Past history of } \\
\text { MI }\end{array}$ & 30 & 19.87 & 61 & 30.65 & 62 & 33.51 & 41 & 29.71 & 2.77 & 0.0407 \\
\hline $\begin{array}{l}\text { Past history of } \\
\text { coronary } \\
\text { intervention }\end{array}$ & 25 & 16.56 & 49 & 24.62 & 40 & 21.62 & 31 & 22.46 & 1.14 & 0.3341 \\
\hline $\begin{array}{l}\text { Stenosis of } \\
\text { Culprit vessel }\end{array}$ & 109 & 72.19 & 154 & 77.39 & $\begin{array}{c}14 \\
2\end{array}$ & 76.76 & $\begin{array}{c}10 \\
7\end{array}$ & 77.54 & 0.55 & 0.6490 \\
\hline $\begin{array}{l}\text { Multiple vessel } \\
\text { coronary lesion }\end{array}$ & 14 & 9.27 & 47 & 23.62 & 40 & 21.62 & 42 & 30.43 & 7.04 & 0.0001 \\
\hline EF>45\% & 118 & 78.15 & 123 & 61.81 & 94 & 50.81 & 65 & 47.10 & 12.90 & $<0.0001$ \\
\hline EF - 35-45\% & 25 & 16.56 & 57 & 28.64 & 66 & 35.68 & 52 & 37.68 & 6.82 & 0.0002 \\
\hline EF<35\% & 8 & 5.30 & 19 & 9.55 & 25 & 13.51 & 21 & 15.22 & 3.10 & 0.0261 \\
\hline $\begin{array}{l}\text { Foci of regional } \\
\text { asynergy }\end{array}$ & 98 & 64.90 & 165 & 82.91 & $\begin{array}{c}15 \\
1\end{array}$ & 81.62 & 11 & 84.78 & 8.03 & $<0.0001$ \\
\hline $\begin{array}{l}\text { Normal } \\
\text { diastolic } \\
\text { function }\end{array}$ & 56 & 37.09 & 22 & 11.06 & 19 & 10.27 & 11 & 7.97 & 23.66 & $<0.0001$ \\
\hline
\end{tabular}

The incidence of female sex, hypertension, acute MI without ST elevation, CABG frequency (also EF\% - 35-45\%, <35\%), and multiple vessel coronary lesion increases with age. On the other hand, the male sex and EF (ejection fraction) $>45 \%$ case is decreasing with age. In patients with age range of 56-75 years, the occurrence of diabetes, dyslipidemia, and past history of MI increases with age. However, these indices decrease in patients older than 75 years.

Table 3 shows the results of correlation analysis between the indices of collateral circulation and patient age, sex, and acute coronary syndrome indices.

Table 3. Correlations between coronary collateral circulation degrees and acute ischemic heart disease indices

\begin{tabular}{|l|l|l|l|l|l|}
\hline & & rentrop0 & rentrop1 & rentrop2 & rentrop3 \\
\hline$<56$ & $\mathrm{r}$ & $0.174^{* *}$ & 0.003 & $-0.112^{* *}$ & $-0.137^{* *}$ \\
\hline & $\mathrm{p}$ & $<0.001$ & 0.930 & 0.004 & $<0.001$ \\
\hline $56-65$ & $\mathrm{r}$ & $-0.091^{*}$ & 0.010 & 0.067 & 0.046 \\
\hline & $\mathrm{p}$ & 0.018 & 0.789 & 0.081 & 0.235 \\
\hline $66-75$ & $\mathrm{r}$ & 0.029 & 0.012 & -0.052 & 0.008 \\
\hline & $\mathrm{p}$ & 0.446 & 0.765 & 0.181 & 0.831 \\
\hline$>75$ & $\mathrm{r}$ & $-0.109^{* *}$ & -0.028 & $0.097^{*}$ & $0.080^{*}$ \\
\hline & $\mathrm{p}$ & 0.005 & 0.469 & 0.012 & 0.038 \\
\hline \multirow{2}{*}{ Female } & $\mathrm{r}$ & -0.059 & -0.039 & $0.079^{*}$ & 0.035 \\
\cline { 2 - 6 } & $\mathrm{p}$ & 0.125 & 0.318 & 0.041 & 0.362 \\
\hline \multirow{2}{*}{ Hypertension } & $\mathrm{r}$ & -0.013 & -0.039 & -0.003 & 0.070 \\
\cline { 2 - 6 } & $\mathrm{p}$ & 0.746 & 0.318 & 0.936 & 0.071 \\
\hline \multirow{2}{*}{ Diabetes } & $\mathrm{r}$ & $-0.094^{*}$ & 0.061 & 0.062 & -0.002 \\
\cline { 2 - 6 } & $\mathrm{p}$ & 0.015 & 0.111 & 0.108 & 0.955 \\
\hline \multirow{2}{*}{ Dyslipidemia } & $\mathrm{r}$ & $-0.077^{*}$ & 0.043 & 0.069 & -0.017 \\
\cline { 2 - 6 } & $\mathrm{p}$ & 0.045 & 0.268 & 0.072 & 0.656 \\
\hline
\end{tabular}




\begin{tabular}{|c|c|c|c|c|c|}
\hline \multirow{2}{*}{ Acute MI with ST elevation } & $\mathrm{r}$ & $<0.001$ & 0.019 & -0.002 & -0.019 \\
\hline & $\mathrm{p}$ & 0.991 & 0.631 & 0.968 & 0.624 \\
\hline \multirow{2}{*}{ Acute MI without ST elevation } & $\mathrm{r}$ & -0.028 & -0.027 & -0.023 & $0.109^{* *}$ \\
\hline & $\mathrm{p}$ & 0.473 & 0.481 & 0.543 & 0.005 \\
\hline \multirow{2}{*}{ Unstable angina } & $\mathrm{r}$ & 0.029 & 0.009 & 0.026 & $-0.094^{*}$ \\
\hline & $\mathrm{p}$ & 0.448 & 0.816 & 0.499 & 0.015 \\
\hline \multirow{2}{*}{ Angina more than 5 years $>$} & $\mathrm{r}$ & $-0.216^{* *}$ & -0.044 & $0.163^{* *}$ & $0.184^{* *}$ \\
\hline & $\mathrm{p}$ & $<0.001$ & 0.256 & $<0.001$ & $<0.001$ \\
\hline \multirow{2}{*}{ TIA } & $\mathrm{r}$ & $-0.097^{*}$ & 0.068 & 0.028 & 0.043 \\
\hline & $\mathrm{p}$ & 0.011 & 0.080 & 0.471 & 0.268 \\
\hline \multirow{2}{*}{ Past history of MI } & $\mathrm{r}$ & $-0.147^{* *}$ & 0.054 & $0.076^{*}$ & 0.073 \\
\hline & $\mathrm{p}$ & $<0.001$ & 0.161 & 0.048 & 0.057 \\
\hline \multirow{2}{*}{$\begin{array}{l}\text { Past history of coronary } \\
\text { angioplasty or bypass }\end{array}$} & $\mathrm{r}$ & -0.054 & $0.083^{*}$ & 0.020 & -0.036 \\
\hline & $\mathrm{p}$ & 0.160 & 0.031 & 0.598 & 0.345 \\
\hline \multirow{2}{*}{$\mathrm{LM}$} & $\mathrm{r}$ & $-0.155^{* *}$ & 0.023 & 0.042 & $0.170^{* *}$ \\
\hline & $\mathrm{p}$ & $<0.001$ & 0.545 & 0.276 & $<0.001$ \\
\hline \multirow{2}{*}{ LAD } & $\mathrm{r}$ & $-0.200^{* * *}$ & -0.039 & $0.135^{* *}$ & $0.191^{* *}$ \\
\hline & $\mathrm{p}$ & $<0.001$ & 0.314 & $<0.001$ & $<0.001$ \\
\hline \multirow{2}{*}{ RCA } & $\mathrm{r}$ & $-0.181^{* *}$ & -0.069 & $0.146^{* *}$ & $0.179^{* *}$ \\
\hline & $\mathrm{p}$ & $<0.001$ & 0.072 & $<0.001$ & $<0.001$ \\
\hline \multirow{2}{*}{ LCX } & $\mathrm{r}$ & $-0.152^{* * *}$ & -0.005 & 0.018 & $0.229^{* *}$ \\
\hline & $\mathrm{p}$ & $<0.001$ & 0.901 & 0.637 & $<0.001$ \\
\hline \multirow{2}{*}{ Stenosis of Culprit vessel } & $\mathrm{r}$ & $-0.105^{* *}$ & 0.021 & $0.145^{* *}$ & -0.049 \\
\hline & $\mathrm{p}$ & 0.006 & 0.585 & $<0.001$ & 0.209 \\
\hline \multirow{2}{*}{ Multiple vessel coronary lesion } & $\mathrm{r}$ & $-0.316^{* *}$ & $-0.086^{*}$ & $0.174^{* *}$ & $0.382^{* *}$ \\
\hline & $\mathrm{p}$ & $<0.001$ & 0.026 & $<0.001$ & $<0.001$ \\
\hline \multirow{2}{*}{$E F>45 \%$} & $\mathrm{r}$ & $0.091^{*}$ & 0.025 & -0.032 & $-0.135^{\text {** }}$ \\
\hline & $\mathrm{p}$ & 0.018 & 0.515 & 0.407 & $<0.001$ \\
\hline \multirow{2}{*}{$E F-35-45 \%$} & $\mathrm{r}$ & -0.049 & -0.027 & 0.042 & 0.055 \\
\hline & $\mathrm{p}$ & 0.206 & 0.477 & 0.279 & 0.151 \\
\hline \multirow{2}{*}{$\mathrm{EF}-\mathrm{Up}$ to $35 \%$} & $\mathrm{r}$ & -0.072 & 0.001 & -0.011 & $0.132^{* *}$ \\
\hline & $\mathrm{P}$ & 0.062 & 0.988 & 0.777 & 0.001 \\
\hline \multirow{2}{*}{ Sites of regional asynergy } & $\mathrm{r}$ & $-.096^{*}$ & 0.044 & 0.062 & 0.021 \\
\hline & $\mathrm{p}$ & 0.013 & 0.255 & 0.109 & 0.585 \\
\hline \multirow{2}{*}{ Normal diastolic function } & $\mathrm{r}$ & $0.154^{* * *}$ & -0.036 & $-0.094^{*}$ & $-0.083^{*}$ \\
\hline & $\mathrm{p}$ & $<0.001$ & 0.346 & 0.015 & 0.032 \\
\hline
\end{tabular}

Rentrop 0 - absence of coronary collateral pathways - shows a significantly positive correlation with $\mathrm{EF}>45 \%$ and normal diastolic function with age $<56$ years. However, it shows negative correlation with diabetes, dyslipidemia, past history $>5$ years, TIA, past MI, LM, LAD, RCA, LCX, stenosis of culprit vessel, multiple vessel coronary lesion, age 66-75, >75, and sites of regional synergy. Retrop 1 shows confidently positive correlation with multiple vessel coronary lesion and past history of coronary angioplasty or bypass. Retrop 2 shows confidently positive correlation with age > 75years, female sex, past history $>5$ years, past history of MI, LAD, RCA, stenosis of 
culprit vessel, multiple vessel coronary lesion, and negative correlation with normal diastolic function for age $<56$ years. Retrop 3 shows clearly positive correlation with age $>75$ years, acute MI without ST elevation, past history $>$ 5 years, LM, LAD, RCA, LC, multiple vessel coronary lesion, and $\mathrm{EF}<35 \%$. However, negative correlation is observed with age $<56$ years, unstable steno cardia, EF $>45 \%$, and normal diastolic function.

\section{Discussion}

Definitive diagnostic data on the effects of aging on collaterals in humans are very limited (Epstein et al., 2012). While studying collateral development with age, it was observed that though the prevalence of coronary collaterals was highest in Group 51 to 70 years, but prevalence of adequate collaterals (Rentrop 2-3) were seen to be increasing with age. In cases with age > 50 years, collaterals were significantly more prevalent compared to less than 50 years (Puri, 2017). Nakae et al. also observed higher prevalence of collaterals among cases with age ranging from 55 - 63 years (Nakae et al., 2000), but well developed collaterals were less documented in older patients in their study group. Also, Pohl et al. did not find any significant correlation between age and collateral development (measured by coronary flow index) (Pohl et al., 2001). According to other data, High-grade collaterals were significantly more in middle-aged individuals compared to the elderly (Chandra et al., 2019). This study showed that absence of collateral circulation correlates with age less than 56 years. The minimal age of patients on rentrop 0 group is 27 years, while the minimal age of patients who show the presence of collateral circuits is more than 64 years and increases with the degree of development of collateral pathways. Age less than 56 years shows confidently positive correlation with absence of collateral circulation. Also, a positive correlation exists with 2 and 3 degree rentrop. 56-65 age groups have negative correlation with absence of collaterals. The authors concluded that advanced age was an independent factor predicting impaired collateral circulation (Kurotobi et al., 2004) which is not confirmed by this study. Age $>75$ years shows confidently negative correlation with rentrop 0 and confidently positive correlation with 2 and 3 degrees. According to literature, good coronary collateral circulation has an indirect beneficial effect on the prognosis for primary PCI. Moreover, a longer time after onset and a more advanced age are associated with higher mortality (Chu et al., 2019).

The factors influencing the collateralization, whose cases increases with age, can also involve diabetes and dyslipidemia. According to our study, this shows a negative correlation with rentrop 0 and their rate is obviously lower in patients aged $<56$ years. This also accounts for the absence of collaterals in young age. TG/HDL ratio is an independent risk factor for predicting poor development of CCC in elderly patients with STEMI and acute 
total occlusion (Liu et al., 2018). According to this study, Retrop 0 shows significantly negative correlation with dyslipidemia.

This data is confirmed by authors as diabetic patients with CAD develop more extensive coronary collateral circulation than nondiabetic subjects, especially men aged $<55$ years. The collateral circulation mainly develops at the LAD and RCA. Patients with diabetes mellitus were observed to have III degree collateral circulation more frequently compared with patients without diabetes (13.2 vs $8.5 \%, \mathrm{p}<0.01)$. This conclusion was further outlined in male patients with diabetes aged $<55$ years. It was also compared with male patients without diabetes $(20$ vs $3.4 \%, \mathrm{p}<0.001)$ and female patients with diabetes (20 vs $2.2 \%, \mathrm{p}<0.001)$.

It was confirmed that III degree collateral circulation develops more during complete occlusion of arteries arising from anterior descendent (LAD) and right coronary artery (RCA) (Melidonis et al., 1999). According to this data, collateral circulation developed during lesion of both LAD and RCA, as well as LCX. In case of LM, collateralization degree is low and does not show confident correlation with rentrop. LAD, LCX, and RCA incidence increases with rentrop degree. Due to the function of $\mathrm{LV}$, patients with better coronary collateral grades had a higher importance EF (Ajayiet al., 2017). Patients with coronary artery disease reportedly have an impaired left ventricular filling (Nii et al., 1994). It is suggested that coronary collaterals are important in preserving left ventricular systolic and diastolic performance. Not readily visible collaterals may also prevent systolic dysfunction (Carmel et al., 1998). The data EF $>45 \%$ shows clearly positive correlation with rentrop 0 and negative correlation with rentrop 2-3 at the same time. EF $>45 \%$ incidence confidently decreases with age, which also can be considered as a reason for growing degree of collateralization with age. Normal diastolic function shows vividly positive correlation with rentrop 2 and 3 and negative correlation with rentrop 0 . The diameter of the coronary arteries were larger in male subjects than females (ShukrI et al., 2014). Males showed higher degree of collateral circulation compared to females (Liu et al., 2017). This paper shows that the cases of female sex increases with age which correlates with rentrop 2.

More extensive studies are recommended to verify these results, in particular, at the molecular and cellular level.

\section{Conclusion}

In conclusion, collateral circulation shows significantly positive correlation with age and especially in female sex. However, it should be considered that in elderly patients with a high ejection fraction and normal diastolic function, the development of collateral vessels is low. 


\section{References:}

1. Ajayi, NO., Vanker, EA., \& Satyapal, KS. (2017). The role of coronary artery collaterals in the preservation of left ventricular function: a study to address a long-standing controversy. Cardiovasc J Afr. 28(2):81-85.

2. Balci, B. \& Yilmaz, O. (2004). Extent of coronary collateral vessel decrease with advanced age. Actacardiol, 59(4), 431-434.

3. Bhatnagar, U. B., Nelson, G., \& Stys, A. (2019). Collateral Flow Reversal: Exploring Protective Role of Collateral Circulation in Acute Coronary Syndrome. South Dakota Medicine, 72(4).

4. Carmel, S., Gueron, M., \& Ilia, R. (1998). Patients with coronary collaterals and normal left ventricular systolic function: clinical, hemodynamic, and angiographic characteristics. Angiology, 49(8), 631-635.

5. Chandra, S., Sanganagoudar, S., Chaudhary, G. K., Dwivedi, S. K., Narain, V. S., Sethi, R., \& Bhandari, M. (2019). Determinants of coronary collateral formation in patients with acute ST-elevation myocardial infarction and total occlusion of infarct-related artery. Heart India, 7(2), 74.

6. Chu, A.A., Li, W., Zhu, Y.Q., Meng, X.X., \& Liu, G.Y. (2019). Effect of coronary collateral circulation on the prognosis of elderly patients with acute ST-segment elevation myocardial infarction treated with underwent primary percutaneous coronary intervention. Medicine, 98(31), e16502.

7. Dai, Y., Chang, S., Wang, S., Shen, Y., Li, C., Huang, Z., \& Zhang, F. (2020). The preservation effect of coronary collateral circulation on left ventricular function in chronic total occlusion and its association with the expression of vascular endothelial growth factor A. Advances in Clinical and Experimental Medicine, 29(4), 493-497.

8. Epstein, S. E., Lassance-Soares, R. M., Faber, J. E., \& Burnett, M. S. (2012). Effects of aging on the collateral circulation, and therapeutic implications. Circulation, 125(25), 3211-3219.

9. Kurotobi, T., Sato, H., Kinjo, K., Nakatani, D., Mizuno, H., Shimizu, M., Imai, K., Hirayama, A., Kodama, K., \& Hori, M. (2004). OACIS Group. Reduced collateral circulation to the infarct-related artery in elderly patients with acute myocardial infarction. J Am CollCardiol. 44:28-34.

10. Liu, G. Y., Meng, X. X., \& Zhang, Z. (2018). Triglyceride to HDLcholesterol ratio as an independent risk factor for the poor development of coronary collateral circulation in elderly patients with ST-segment elevation myocardial infarction and acute total occlusion. Medicine, 97(39), e12587 
11. Liu, Z., Pericak-Vance, M. A., Goldschmidt-Clermont, P., Seo, D., Wang, L., Rundek, T., \& Beecham, G. W. (2017). Coronary collateralization shows sex and racial-ethnic differences in obstructive artery disease patients. PloS one; 12(10), e0183836.

12. Meier, P., Schirmer, S. H., Lansky, A. J., Timmis, A., Pitt, B., \& Seiler, C. (2013). The collateral circulation of the heart. BMC medicine, 11, 143-150.

13. Melidonis, A., Tournis, S., Kouvaras, G., Baltaretsou, E., Hadanis, S., Hajissavas, I., ... \& Foussas, S. (1999). Comparison of coronary collateral circulation in diabetic and nondiabetic patients suffering from coronary artery disease. $\mathrm{Cl}$ cardiol, 22(7), 465-471.

14. Nakae, I., Fujita, M., Miwa, K., Hasegawa, K., Kihara, Y., Nohara, R., ... \& Sasayama, S. (2000). Age-dependent impairment of coronary collateral development in humans. Heart Vessels., 15(4), 176-180.

15. Nii, T., Tsuchiya, Y., Tahara, H., Imamura, M., Nakashima, Y., \& Arakawa, K. (1994). Coronary collateral circulation and diastolic function. Int J Cardiol. 44(1), 37-44.

16. Pohl, T., Seiler, C., Billinger, M., Herren, E., Wustmann, K., Mehta, H., Windecker, S., Eberli, FR., \& Meier, B. (2001). Frequency distribution of collateral flow and factors influencing collateral channel development: Functional collateral channel measurement in 450 patients with coronary artery disease. J Am Coll Cardiol. 38(7):1872-8.

17. Puri, D. \& Puri, N. (2017). Angiographic Evaluation of Coronary Collateral Circulation Patterns in Patients with Coronary Artery Disease Requiring Surgical Revascularization. World Journal of Cardiovascular Diseases, 7(11), 380-389

18. Seiler, C., Stoller, M., Pitt, B., \& Meier, P. (2013). The human coronary collateral circulation: development and clinical importance. Eur Heart J, 34(34), 2674-2682.

19. Seiler, C. (2010). The human coronary collateral circulation. European journal of clinical investigation, 40(5), 465-476.

20. Shukri, I. G., Hawas, J. M., Karim, S. H., \& Ali, I. K. M. (2014). Angiographic study of the normal coronary artery in patients attending ulaimani center for heart diseases. European Scientific Journal, 10(24): p.384-415.

21. Ucak, H. A. \& Uncu, H. (2019, September). Impact of Coronary Collateral Circulation of Perioperative Myocardial Damage in HighRisk Patients Undergoing Coronary Artery Bypass Grafting Surgery. In The heart surgery forum (Vol. 22, No. 5, pp. E375-E379). 
22. Wang, M., Monticone, RE., \& Lakatta, EG. (2010). Arterial aging: a journey into subclinical arterial disease. Curr Opin Nephrol Hypertens. 19:201-207.

23. Zimmerman, F.H., Cameron, A., \& Fisher, L.D. (2005). Myocardial infarction in young adults: angiographic characterization, risk factors and prognosis (Coronary Artery Surgery Study Registry). J. Am.Coll. Cardiol. 26 (3). 654-61. 